\title{
EXPERIMENTAL RESULTS ON VISIBILITY THRESHOLD AND CALCULATION OF JND BASED on Human Visual Perception
}

\author{
KUZMANIC, I.; BEROS, S.M. \& VUJOVIC, I.
}

Abstract: The distortion of the images transmitted over satellite channel can noticeably depend on various conditions and circumstances. In telemedical images, the distortion can be fatal and result in misdiagnosis and wrong treatment. Satellite communication for application in telemedicine is considered. The results have shown that just-noticeable-distortion can lead to misdiagnosis in the case of transmission of pulmonary X-ray images and it is concluded that the area of telemedical use of JND profile must be carefully chosen. Human visual perception of grey images is investigated, performed experiments and calculated the JND for the experimented case. Minimal fatal error distortion (MFED) is introduced and some aspects of it are discussed. The JND of the X-ray original and the distorted image is calculated and shown that JND difference can be used to locate the distortion.

Key words: human visual perception, just-noticeable-distortion, minimal fatal error distortion, satellite communication, telemedicine images
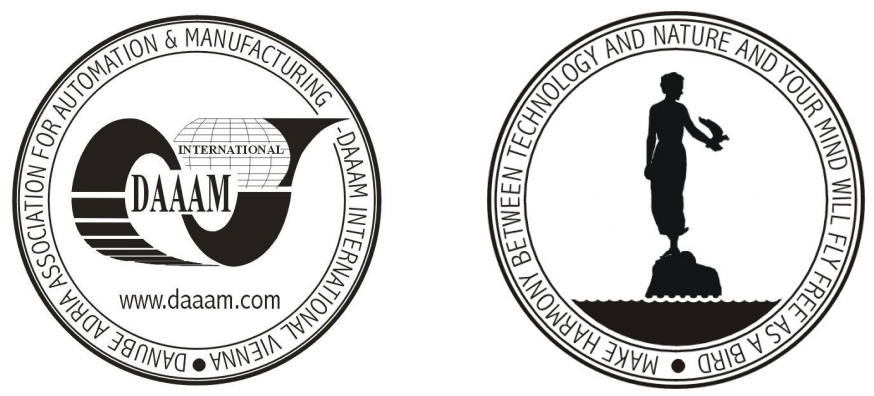

Authors' data: Mr. sc. Kuzmanic, I[vica]*; Dr. sci. Beros, S[lobodan] M[arko]; Mr. sc. Vujovic, I[gor]*; Maritime Faculty, * University of Split, Zrinsko-Frankopanska 38, 21000 Split, Croatia, University of Split, FESB ECE Dept., Boskovica bb., 21000 Split, Croatia, ikuzman@pfst.hr, sberos@fesb.hr, ivujovic@pfst.hr

This Publication has to be referred as: Kuzmanic, I.; Beros, S.M. \& Vujovic, I. (2007). Collaborative Experimental Results on Visibility Threshold and Calculation of JND Based on Human Visual Perception, Chapter 21 in DAAAM International Scientific Book 2007, B. Katalinic (Ed.), Published by DAAAM International, ISBN 3-901509-60-7, ISSN 1726-9687, Vienna, Austria

DOI: $10.2507 /$ daaam.scibook.2007.21 